\title{
Spontaneous Pneumothorax with Persistent Air Leakage and Invasive Procedures
}

\author{
Takahiro Haga, Masatoshi Kurihara and Hideyuki Kataoka
}

\begin{abstract}
Objective Prolonged air leaks in patients with spontaneous pneumothorax are not infrequent. The aim of this study was to assess the duration of air leaks and define the clinical variables associated with the therapeutic success of chest tube drainage for spontaneous pneumothorax.

Methods A total of 441 patients with spontaneous pneumothorax treated with chest tube drainage between 2008 and 2012 were retrospectively evaluated. The clinical differences between the patients successfully treated with drainage and those who required more invasive procedures were analyzed.

Results Invasive procedures, such as video-assisted thoracic surgery $(\mathrm{n}=121)$, fibrin glue administration through a chest tube $(n=8)$ and pleurodesis with OK-432 $(n=21)$, were performed in $34 \%(150 / 441)$ of the patients. The treatment rate of chest drainage alone was higher in the patients with initial pneumothorax $(72 \% ; 124 / 170)$ than in those with recurrent pneumothorax $(62 \% ; 167 / 271)(\mathrm{p}=0.015)$. In addition, this rate was higher in the patients with moderate lung collapse $(70 \%$; 167/237) than in those with severe lung collapse $(61 \%$; 124/204) ( $\mathrm{p}=0.032)$.
\end{abstract}

Conclusion Patients with recurrent pneumothorax or severe lung collapse associated with prolonged air leakage are more likely to receive invasive procedures.

Key words: spontaneous pneumothorax, persistent air leak, chest tube drainage, video-assisted thoracic surgery

(Intern Med 52: 2189-2192, 2013)

(DOI: 10.2169/internalmedicine.52.0732)

\section{Introduction}

The objective of treating pneumothorax is to achieve the reexpansion of the collapsed lung and prevent recurrence (1). In patients with symptomatic pneumothorax, the use of needle aspiration and chest tube drainage is generally recommended (1-3). Recently, needle aspiration and chest tube drainage have been reported to be equally effective, with success rates of up to $80 \%$ (4-6).

When persistent air leaks continue, invasive procedures, such as video-assisted thoracic surgery (VATS) or pleurodesis, are required. However, conversion to invasive procedures in pneumothorax patients with prolonged air leakage requires skilled clinical judgment. Pneumothorax may resolve spontaneously in a large proportion of patients, who do not require invasive procedures, while other pneumothorax pa- tients have a high risk of respiratory infection, empyema formation and deep venous thrombosis due to the inappropriate use of VATS $(7,8)$.

There are several reports regarding the time course and clinical variables predictive of a recovery following chest tube drainage in patients with pneumothorax (9-11). International guidelines for the management of pneumothorax include indications for referral to a thoracic surgeon. These guidelines recommend that pneumothorax patients with prolonged air leaks lasting more than either five to seven days (2) or four days (1) should be referred to a thoracic surgeon. However, the time limits included in these guidelines remain undefined. Chee et al. showed that 30 of 31 (97\%) cases of primary pneumothorax and 59 of 73 (79\%) cases of secondary pneumothorax resolved following treatment with chest tube drainage alone (11). They concluded that pneumothorax patients with prolonged air leaks lasting 
Table 1. Comparison of Previous Reports and the Present Study Regarding the Proportion of Patients who Required Invasive Procedures and the Risk Factors for Invasive Treatment

\begin{tabular}{lrrlr}
\hline Author (Ref) & $\begin{array}{l}\text { No of } \\
\text { patients }\end{array}$ & $\begin{array}{l}\text { Patients } \\
\text { required } \\
\text { invasive } \\
\text { procedures } \\
(\%)\end{array}$ & $\begin{array}{l}\text { Risk factors required invasive } \\
\text { treatments }\end{array}$ & Year \\
\hline $\begin{array}{l}\text { Schoenenberger } \\
\text { (9) }\end{array}$ & 115 & 13.9 & Secondary pneumothorax & 1991 \\
Mathur (10) & 143 & 20.4 & Secondary pneumothorax & 1995 \\
Chee (11) & 104 & 3.8 & $\begin{array}{l}\text { Secondary pneumothorax } \\
\text { Severe extent of lung collapse }\end{array}$ & 2013 \\
Haga & 441 & 34 & \begin{tabular}{l} 
Recurrent pneumothorax \\
\hline
\end{tabular} \\
\hline
\end{tabular}

over 14 days should undergo invasive procedures. In contrast, Schoenenverger et al. showed that the healing rate of pneumothorax treated with chest tube drainage reaches a maximum at two days, even if drainage is maintained for up to 10 days (9). They indicated that early conversion to invasive procedures in patients with air leaks lasting for more than two days is justified. These differences in time limits may be due to the lack of identification of risk factors for treatment failure. Having awareness of risk factors for treatment failure is necessary for making the decision to refer pneumothorax patients to thoracic surgeons. To our knowledge, the reported risk factors for treatment failure following chest tube drainage include the presence of underlying pulmonary diseases (9-11) (Table 1).

Therefore, the aim of this study was to assess the duration of air leaks and identify clinical variables predictive of the therapeutic success of chest tube drainage for pneumothorax in the Japanese clinical setting. To our knowledge, this is the first large-scale study to evaluate persistent air leakage and invasive procedures in patients with spontaneous pneumothorax, although this is a retrospective investigation.

\section{Materials and Methods}

The clinical files and chest X-rays of all patients admitted for treatment of pneumothorax with chest tube drainage at Nissan Tamagawa Hospital over the five years between January 2008 and December 2012 were retrospectively reviewed. In our hospital, pneumothorax patients without severe symptoms, such as dyspnea, are treated in an outpatient setting with observation, needle aspiration or portable drainage units (consisting of a flexible 9-Fr drainage catheter and a small plastic chamber with two one-way valves).

Pneumothorax patients with severe symptoms are treated in an inpatient setting using chest tube drainage. The extent of lung collapse on chest X-rays was defined as follows: 1) mild: collapse of less than one-third of the lung fields; 2) moderate: collapse of more than one-third of the lung fields; or 3) severe: complete collapse of the lungs. After confirming the diagnosis of pneumothorax on chest X-rays, an 18Fr drainage catheter was inserted into the fifth intercostal space at the midaxillary line. The chest tube was maintained

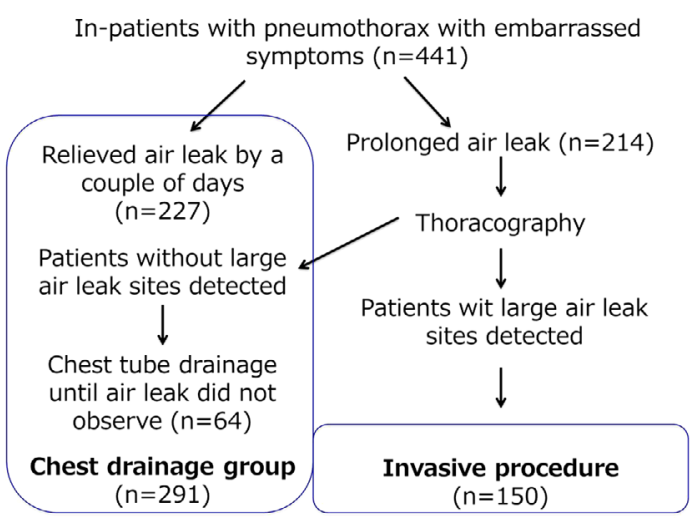

Figure. Treatment protocol

under continuous drainage applied at less than $20 \mathrm{cmH}_{2} \mathrm{O}$.

The presence of air leakage was evaluated by two experts. If the air leak stopped within two or three days after performing chest tube drainage, the chest tube was clamped for 24 hours and the tube was removed, unless a chest X-ray demonstrated lung collapse. Patients with prolonged air leaks underwent thoracography to assess the air leak site and lung volume a few days after tube drainage. A few patients with apparently large air leaks underwent thoracography on the day of tube drainage.

Patients without large air leak sites detected on thoracography were maintained under continuous drainage until the air leak was no longer observed. All patients without large air leak sites based on the thoracography findings were successfully treated with chest drainage alone. Patients with large air leak sites detected on thoracography were treated with more invasive procedures, such as VATS, interventional treatment with fibrin glue administered through a chest tube and pleurodesis with OK-432 (Figure). Invasive procedures were generally performed within two weeks from thoracography, and no patients with large air leak sites based on the thoracography findings were successfully treated without invasive procedures.

We assessed the age, sex, underlying diseases, history of pneumothorax and duration and extent of lung collapse between the patients who received chest tube drainage and those who received more invasive procedures. The chest drainage group consisted of two subgroups: (1) patients in which the air leakage stopped within two or three days and (2) patients in which the site of air leakage could not be detected on thoracography and, therefore, chest tube drainage was continued until the air leak was no longer observed.

This study was approved by the institutional review board of Nissan Tamagawa Hospital. Quantitative data are presented as the mean \pm SD. Differences between the patients treated with chest tube drainage and those treated with more invasive procedures were analyzed with the chi-square test for categorical variables and Student's $t$-test for quantitative variables. A p value of $<0.05$ was considered to be significant. A statistical software package (StatView, version 5.0; SAS Institute; Cary, NC, USA) was used for the statistical 
Table 2. The Clinical Characteristics of the Patients

\begin{tabular}{lrrr}
\hline Treatment & $\begin{array}{l}\text { Treated by drainage } \\
\text { alone; } \\
\mathrm{n}=291\end{array}$ & $\begin{array}{l}\text { Needed invasive } \\
\text { procedures; } \\
\mathrm{n}=150\end{array}$ & $\mathrm{p}$ value \\
\hline Age & $40.0 \pm 19.9$ & $42.5 \pm 22.8$ & 0.25 \\
Sex & $229(78.7 \%)$ & $122(81.3 \%)$ & 0.52 \\
Male & $62(21.3 \%)$ & $28(18.7 \%)$ & \\
Female & & & \\
Underlying disease & $226(77.7 \%)$ & $107(71.3 \%)$ & 0.09 \\
Blebs & $11(3.8 \%)$ & $5(3.3 \%)$ & 0.81 \\
Bronchial asthma & $28(9.6 \%)$ & $21(14.0 \%)$ & 0.17 \\
COPD & $8(2.7 \%)$ & $5(3.3 \%)$ & 0.73 \\
Interstitial pneumonia & $2(0.7 \%)$ & $7(4.7 \%)$ & 0.01 \\
Mycobacterium Infection & $11(3.8 \%)$ & $2(1.3 \%)$ & 0.15 \\
LAM & $1(0.3 \%)$ & $1(0.7 \%)$ & 0.63 \\
BHD syndrome & $4(1.4 \%)$ & $2(1.3 \%)$ & 0.97 \\
Catamenial pneumothorax & & &
\end{tabular}

COPD: Chronic obstructive pulmonary disease,

LAM: Lymphangioleiomyomatosis, BHD: Birt-Hogg-Dube

analysis.

\section{Results}

A total of 441 patients with pneumothorax were treated with chest tube drainage. The clinical characteristics of the patients are shown in Table 2. Invasive procedures, such as VATS $(n=121)$, interventional treatment with fibrin glue administered through a chest tube $(n=8)$ and pleurodesis with OK-432 $(n=21)$, were performed in $150(34 \%)$ of the 441 patients.

The duration of the air leak was $2.4 \pm 4.0$ (0-35) days in the patients treated with chest tube drainage alone. The duration of the air leak was $9.6 \pm 3.3(1-24)$ days in the patients who required invasive procedures. A total of $73 \%(124 / 170)$ of the patients with initial pneumothorax were successfully treated with chest tube drainage compared with $62 \%$ (167/ 271) of those with recurrent pneumothorax $(\mathrm{p}=0.015)$. A total of $70 \%(167 / 237)$ of the patients with moderate lung collapse were successfully treated with chest tube drainage compared with $61 \%(124 / 204)$ of those with severe lung collapse $(p=0.032)$. A total of $68 \%(226 / 333)$ of the patients with primary pneumothorax were successfully treated with chest tube drainage alone compared with 60\% (65/108) of those with secondary pneumothorax $(\mathrm{p}=0.143)$ (Table 3$)$.

\section{Discussion}

The present study has important strengths compared to previously reported studies. The present study was a clinical study comprising the largest patient population evaluated thus far. At the Pneumothorax Research Center, which specializes in the treatment of pneumothorax, we were able to recruit a large number of patients $(n=441)$. A limitation of our study is the lack of detail in the clinical histories and conditions of the patients because we analyzed the clinical records retrospectively.

In the present study, the duration of the air leak was $2.4 \pm$ 4.0 days in the patients treated with chest tube drainage
Table 3. Comparison of the Subjects Treated with Chest Tube Drainage and Those Treated with Invasive Procedures

\begin{tabular}{lrrr}
\hline Treatment & $\begin{array}{l}\text { Chest drainage; } \\
\mathrm{n}=291\end{array}$ & $\begin{array}{l}\text { Invasive } \\
\text { procedures; } \\
\mathrm{n}=150\end{array}$ & $\mathrm{p}$ value \\
\hline $\begin{array}{l}\text { Initial / Recurrent } \\
\text { pneumothorax }\end{array}$ & $124 / 167$ & $46 / 104$ & 0.02 \\
$\begin{array}{l}\text { Extent of lung collapse } \\
\text { Mild / Moderate / Severe }\end{array}$ & $0 / 167 / 124$ & $0 / 70 / 80$ & 0.03 \\
$\begin{array}{l}\text { Primary / Secondary } \\
\text { pneumothorax }\end{array}$ & $226 / 65$ & $107 / 43$ & 0.14 \\
\hline
\end{tabular}

* Secondary pneumothorax: pneumothorax with underlying pulmonary disease other than blebs.

alone. The duration of the air leak was 9.6 \pm 3.3 days in the patients who required invasive procedures. The rate of successful treatment with chest drainage alone was higher in the patients with initial pneumothorax $(72 \% ; 124 / 170)$ than in those with recurrent pneumothorax $(62 \%$; 167/271) $(\mathrm{p}=$ $0.015)$. In addition, this rate was higher in the patients with moderate lung collapse $(70 \%$; 167/237) than in those with severe lung collapse $(61 \% ; 124 / 204)(\mathrm{p}=0.032)$. Therefore, patients with recurrent pneumothorax or severe lung collapse associated with prolonged air leakage are more likely to receive invasive procedures.

The major feature of our practice in pneumothorax patients is thoracography. The thoracographic findings indicate the location, number and size of the bullae. Furthermore, both the size and degree of the air leak can be estimated (12-14). In the present study, all of the patients with the air leaks prolonged over two or three days underwent thoracography. A total of $70 \%(150 / 214)$ of the patients who underwent thoracography were found to have large air leak sites. Large air leak sites often do not resolve spontaneously. Therefore, all pneumothorax patients with large air leak sites were treated with invasive procedures.

Although we actively performed invasive procedures in the pneumothorax patients with large air leaks, some of these patients may have eventually demonstrated spontaneous resolution without undergoing such procedures. Indeed, the rate of patients who required invasive procedures was higher in the present study (34\%) than that reported in previous studies (3.8-20.4\%) (9-11). Pneumothorax patients treated with a longer duration of chest tube drainage are reported to have a high risk for developing respiratory infection, empyema formation and deep venous thrombosis $(7,8)$. We believe that our strategy, namely conversion to invasive procedures in pneumothorax patients with prolonged air leaks based on thoracographic findings, is therefore justified, considering the risks associated with longterm chest tube drainage.

In previous studies, the presence of underlying pulmonary diseases has been reported to be a risk factor for treatment failure following chest tube drainage (9-11). Although the present study showed that the rate of healing in the patients with secondary pneumothorax was lower than that in the pa- 
tients with primary pneumothorax, this difference was not statistically significant. It may be that differences in the therapeutic strategies and underlying diseases encountered in each institution contributed to the statistical differences. Our results demonstrated a low rate of healing depending on the presence of recurrent pneumothorax or severe lung collapse. Based on these results, we propose that patients with recurrent pneumothorax or severe lung collapse with prolonged air leaks should receive earlier referrals to thoracic surgeons.

\section{Conclusion}

In conclusion, the results of our study suggest that patients with recurrent pneumothorax or severe lung collapse with prolonged air leaks should receive earlier referrals to thoracic surgeons.

The authors state that they have no Conflict of Interest (COI).

\section{References}

1. Baumann MH, Strange C, Heffner JE, et al. Management of spontaneous pneumothorax: an American College of Chest Physicians Delphi consensus statement. Chest 119: 590-602, 2001.

2. Hooper C, Maskell N. British Thoracic Society national pleural procedures audit 2010. Thorax 66: 636-637, 2011.

3. Tschopp JM, Rami-Porta R, Noppen M, Astoul P. Management of spontaneous pneumothorax: state of the art. Eur Respir J 28: 637650, 2006.

4. Nishiuma T, Ohnishi H, Katsurada N, Yamamoto S, Yoshimura S, Kinami S. Evaluation of simple aspiration therapy in initial treat- ment for primary spontaneous pneumothorax. Intern Med 51: 1329-1333, 2012.

5. Liu CM, Hang LW, Chen WK, Hsia TC, Hsu WH. Pigtail tube drainage in the treatment of spontaneous pneumothorax. Am J Emerg Med 21: 241-244, 2003.

6. Noppen M, Alexander P, Driesen P, Slabbunck H, Verstraeten A. Manual aspiration versus chest tube drainage in first episode of primary spontaneous pneumothorax: a multicenter prospective randomized pilot study. Am J Respir Crit Care Med 165: 1240-1244, 2002.

7. Waller DA, McConnell SA, Rajesh PB. Delayed referral reduces the success of video-assisted thoracoscopic sutgery for spontaneous pneumothorax. Respir Med 92: 246-249, 1998.

8. Cobanoglu U, Melek M, Edirne Y. Autologous blood pleurodesis: a good choice in patients with persistent air leak. Ann Thorac Med 4: 182-186, 2009.

9. Schonennerger RA, Haefeli WE, Weiss P, Ritz RF. Timing of invasive procedures in therapy for primary and secondary spontaneous pneumothorax. Arch Surg 126: 764-766, 1991.

10. Mathur R, Cullen J, Kinnear WJ, Johnston ID. Time course of resolution of persistent air leak in spontaneous pneumothorax. Respir Med 89: 129-132, 1995.

11. Chee CB, Abisheganaden J, Yeo JK, et al. Persistent air-leak in spontaneous pneumothorax-clinical course and outcome. Respir Med 92: 757-761, 1998.

12. Kurihara M, Kataoka H, Ishikawa A, Endo R. Latest treatment for spontaneous pneumothorax. Gen Thorac Cardiovasc Surg 58: 113119, 2010.

13. Sugamura Y, Jibiki M, Ikari H, et al. Thoracoscopic surgical treatment of spontaneous pneumothorax: selection of surgical therapy according to thoracoscopic findings. Diagn Ther Endosc 1: 165168, 1995.

14. Takeno Y. Thoracoscopic treatment of spontaneous pneumothorax. Ann Thorac Surg 56: 688-690, 1993.

(C) 2013 The Japanese Society of Internal Medicine http://www.naika.or.jp/imonline/index.html 